\title{
DO OUTRO LADO DO ATLÂNTICO: AS RELAÇÕES POLÍTICAS E ECONÔMICAS ENTRE O BRASIL E OS PAÍSES AFRICANOS DESDE O SÉCULO XX
}

From the other side of the Atlantic: Political and economic relations between Brazil and African countries since the 2oth century

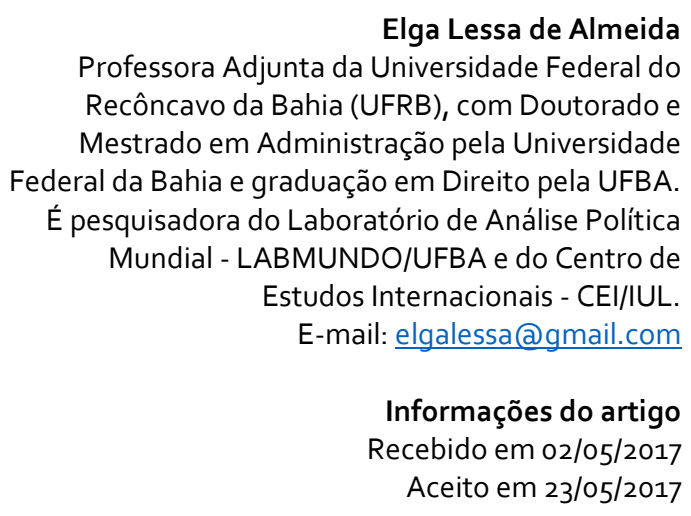

Informações do artigo

Aceito em 23/05/2017

\begin{abstract}
Resumo
A análise dos últimos anos das relações políticas e econômicas entre o Brasil e os países africanos mostram uma tendência para repetição de um padrão presente ao longo de todo o século XX curtos períodos de aproximação seguidos por períodos maiores de afastamento. A importância da herança africana para a formação da sociedade brasileira não se tem refletido na construção de relações estáveis com alguns desses países ou que se dinamizem e se aprofundem ao longo do tempo. Este artigo procura apresentar essa dinâmica de aproximação-afastamento que tem caracterizado essas relações, trazendo elementos que possibilitem compreender a manutenção desse padrão.

Palavras-chave: Brasil. Países africanos. Relações.

Dinâmica.
\end{abstract}

\section{Introdução}

A análise dos últimos anos das relações políticas e econômicas entre o Brasil e os países africanos mostram uma tendência para repetição de um padrão presente ao longo de todo o século XX - curtos períodos de aproximação seguidos por períodos maiores de afastamento. A importância da herança africana para a formação da sociedade brasileira não se tem refletido na construção de relações estáveis com alguns desses países ou que se dinamizem e se aprofundem ao longo do tempo. No âmbito diplomático, diferentes correntes se alternam sobre a importância de se investir nas relações com o continente como alternativa para promoção de uma melhor posição brasileira na política internacional e para conquista de mercado ou se, ao contrário, o continente africano não representa nenhum ganho político ou econômico.

O momento atual é de resfriamento das relações após uma década de intensa promoção dessas relações no governo de Lula da Silva (2003-2010). Nos dois mandatos do governo Lula, as relações com os países africanos ganharam visibilidade e se refletiram no aumento de número de embaixadas, de viagens presidenciais, da cooperação internacional 
para o desenvolvimento, da balança comercial e de investimentos brasileiros no continente. Essa política é, em alguma medida, abandonada no governo de Dilma Rousseff (2011-2016) e, principalmente, nos discursos dos representantes do atual governo Michel Temer, a tendência ao distanciamento do continente é reforçada, resultando na queda da corrente de comércio de $\mathrm{R} \$ 28.533 .453 .431$, em 2013, ápice da corrente de comércio na década, para $\mathrm{R} \$ 12.433 .516 .567$, em 2016, além das notícias recorrentes sobre o fechamento de embaixadas.

É nesse contexto de mudança de orientação na política para o continente africano que se evidencia a necessidade de discutir os desafios presentes nessas relações, que demonstram a existência de fragilidades ainda não superadas desde a segunda metade do século XX. Nesse sentido, este artigo procura apresentar essa dinâmica de aproximaçãoafastamento que tem caracterizado essas relações, trazendo elementos que possibilitem compreender a manutenção desse padrão.

\section{A dinâmica aproximação-afastamento nas relações entre o Brasil e os países africanos}

Para compreender como se estabeleceu esse padrão nas relações entre o Brasil e os países africanos, entende-se necessária uma recapitulação histórica dessas relações. Podem ser observados sete períodos para compreender a intermitência da PEB em relação à África: da abolição da escravatura até o governo Juscelino Kubitschek; os governos Jânio Quadros e João Goulart (1961-1964); o início da ditadura militar (1964-1969); os governos Médici e Geisel (1969-1979); período democrático (pós-1988); o governo Lula da Silva (2003-2010); e o governo Dilma Rousseff (2011-2016). Apesar de muitos fatos históricos repercutirem em mais de um período, ficará claramente identificada a dinâmica de afastamento-aproximação de cada período, além dos fatores domésticos e externos que motivaram a mudança de rumo da política externa brasileira.

Da abolição da escravatura ao governo de Juscelino Kubitschek: afastamento

Historicamente, a relação entre o Brasil e o continente africano iniciou-se no século XVI com a chegada dos primeiros africanos escravizados vindos da costa ocidental inicialmente de Angola e do Congo e, depois, das regiões da Nigéria, Gana, Daomé e Togo 
(RODRIGUES, 1964, a). Até a abolição da escravatura, essa relação limitou-se à escravidão e ao tráfico atlântico de escravos dela decorrente, caindo em absoluta insignificância a partir desse momento, motivada pela intenção deliberada do governo brasileiro em afastar-se do continente africano para a construção de uma imagem de sociedade moderna e ocidental. As relações comerciais permaneceram irrelevantes dado que a maioria dos países africanos continuava sob o jugo colonial e a política dos colonizadores impedia a abertura do comércio (SARAIVA, 2012).

Com o processo de industrialização no pós-Segunda Guerra, a África passou a ser incluída na agenda brasileira: primeiro, porque o protecionismo europeu aos produtos de suas colônias (e, agora, a algumas ex-colônias) africanas poderiam prejudicar as exportações brasileiras; e, segundo, porque os foros internacionais constrangiam a adoção de algum posicionamento sobre o colonialismo na África. Já na década de 1930, a constatação de que os produtos agrícolas oriundos da África estavam em franca expansão no mercado e concorriam com produtos brasileiros despertou a atenção do governo para a questão do mercado privilegiado que se constituía entre as metrópoles europeias e suas colônias. Principalmente, produtos como o algodão, cacau, café e açúcar sofriam uma alta concorrência: Uganda produzia mais algodão que Pernambuco, maior produtor nacional; Gana produzia mais cacau que a Bahia; e a produção de açúcar e café era crescente nas colônias portuguesas, principalmente em Angola (RODRIGUES, 1964, a; GONÇALVES, 2003).

Aliada à expansão agrícola africana, a criação do Mercado Comum Europeu, em 1957, foi outro entrave para as exportações dos produtos primários brasileiros. Sob a liderança francesa, os territórios ultramarinos foram incluídos no sistema fechado de comércio seletivo em que se constituía esse Mercado. Posteriormente, com a independência de algumas colônias, os novos Estados puderam associar-se em um sistema que estabelecia regime preferencial, um fundo de desenvolvimento, a não discriminação entre os Seis (França, Alemanha Ocidental, Itália, Bélgica, Países Baixos e Luxemburgo) e seus associados e um Conselho de Ministros e uma Corte de Justiça próprios. Na prática, a participação de países africanos significou o acesso de seus produtos a esse mercado sem a incidência de tarifas aduaneiras, o que barateava o preço dos mesmos e gerava, por sua vez, uma concorrência desleal para os produtos brasileiros (RODRIGUES, 1964b; SARAIVA, 2012). 
A reação brasileira ao sistema preferencial ocorreu tanto em conferências internacionais, como a Conferência do Cairo realizada em julho de 1962, como em reuniões no âmbito do Acordo Geral sobre Tarifas e Comércio (General Agreement on Tariffs and Trade) - GATT, com a exposição do descontentamento brasileiro e latino-americano. Na XIX Sessão do GATT, a delegação brasileira apontou uma série de medidas retaliatórias que o governo poderia adotar caso tarifas mais vantajosas não fossem negociadas, como a não ratificação de acordos e aumento unilateral de tarifas. A insatisfação de vários países, dentre eles o Brasil, em relação aos sistemas preferenciais e, principalmente, à deterioração das economias subdesenvolvidas pela relação de trocas comerciais com os países desenvolvidos, com o contínuo declínio nos preços dos produtos primários, levou esses países a buscarem medidas comuns junto à ONU, que mais tarde deram origem a algumas conferências como a Conferência das Nações Unidas sobre o Comércio e Desenvolvimento (United Nations Conference on Trade and Development) - UNCTAD, em 1962 (RODRIGUES, 1964, b). É certo que, para o Brasil, o desenvolvimento africano em bases coloniais e, posteriormente, por meio de um sistema preferencial de tarifas não interessava ao país.

Apesar das desvantagens econômicas da manutenção da relação entre as metrópoles europeias e suas colônias (e ex-colônias), o posicionamento brasileiro sobre a questão da descolonização demonstrou a inconsistência da diplomacia brasileira e grande afastamento quanto aos interesses das lideranças africanas. Quando as primeiras colônias africanas e asiáticas conquistaram suas independências - inicialmente as colônias inglesas e francesas e ingressaram na ONU, a pressão desses países sob os membros da Assembleia Geral da organização aumentou consideravelmente, resultando em diversas resoluções cujo objetivo era condenar o colonialismo e estabelecer penalidades aos países que persistissem na manutenção de colônias no continente. Dessas resoluções, observa-se que o Brasil apenas votou a favor em algumas resoluções no período dos governos de Juscelino Kubistchek a João Goulart, votando contra ou abstendo-se nas demais resoluções (DÁVILA, 2011, p. 120-121).

As razões que justificam o posicionamento brasileiro remontam à relação "afetiva" entre Brasil e Portugal, consubstanciada na teoria da democracia racial de Gilberto Freyre e em uma influente colônia portuguesa no Rio de Janeiro (DÁVILA, 2011; MAGALHÃES, 1997; GONÇALVES, 2003; LEME, 2011). A obra "Casa Grande e Senzala" (1933), de Freyre, forneceu as bases para a defesa do sistema colonial português ao longo de toda ditadura de Salazar sob a suposta ideia de uma inclinação especial dos portugueses para a expansão civilizatória 
pelos trópicos e atenuação das diferenças raciais por meio da miscigenação. Segundo Williams Gonçalves (2003), a obra de Gilberto Freyre teria feito mais pela reconciliação entre Brasil e Portugal - relação estremecida desde a proclamação da República - do que os esforços realizados pelos governos, ao mesmo tempo em que forneceu as bases para a fraternidade luso-brasileira que se manifestaria na década de 1950. A importância de Gilberto Freyre não se restringiu à utilização de "Casa Grande e Senzala" como inspiração para a formulação da teoria lusotropicalista, como ficou conhecida a inclinação portuguesa para a colonização dos trópicos, mas residiu em uma aliança especial com o próprio Freyre, que realizou, a convite do governo português, uma série de palestras sobre as virtudes portuguesas no Brasil e em outros países e uma viagem para as colônias portuguesas da qual decorrem dois livros que voltariam a exaltar as qualidades do colonizador português (DÁVILA, 2011; GONÇALVES, 2003).

A ideia de que o Brasil era o perfeito exemplo da mistura democrática de raças empreendida pelo português que resultou em uma sociedade moderna e industrializada foi utilizada pelo governo salazarista para envolver o governo brasileiro na defesa dos interesses portugueses, principalmente na manutenção de suas possessões ultramarinas. Já no primeiro governo de Getúlio Vargas, grande incentivador da aproximação entre Brasil e Portugal, a ideia de formação de uma comunidade luso-brasileira permeava o ideário de governantes brasileiros e portugueses, ideia que acabou não se concretizando mas que forneceu os substratos para a futura assinatura do Tratado de Amizade e Consulta, de 1953. Com o objetivo de institucionalizar a aliança entre os países e harmonizar as políticas externas pelo mecanismo das consultas mútuas, mas, sobretudo, resolver questões práticas como a situação de emigrantes brasileiros e portugueses, o Tratado acabou sendo utilizado pelo governo português para cristalizar o apoio brasileiro na questão das colônias africanas e asiáticas. Rodrigues (1964) explicita bem o "espírito" do Tratado:

Como se vê, os planos grandiosos de pôr-nos a serviço deles não é fruto de pura imaginação megalomaníaca; resulta do pensamento retardatário com que se defendeu a comunidade, dando preeminência a Portugal, ou considerando-a indestrutível, porque baseada no sangue, solidificada por quatro séculos de afeto e comunhão. Resulta, ainda, do pensamento de que jamais devemos assumir atitudes contrárias à velha Mãe Pátria, ou lhe opormos embargos à liberdade com que confunde os nossos e os seus interesses.

$[\ldots]$ 
O Tratado é uma vitória portuguesa, arrastando o Brasil para sua órbita, de acôrdo com as pretensões que citamos antes, visando dispor de nosso apoio nas dificuldades internacionais. Por êle nos obrigamos a consultar Portugal - com suas dependências coloniais sobre matéria internacional, tirando-nos, assim, ou pelo menos dificultando, todo o nosso jogo diplomático (RODRIGUES, 1964b, p. 356-359)

Diferentemente, na visão do chanceler brasileiro à época, Vicente Raó, a assinatura do Tratado representou uma vitória da diplomacia brasileira que passaria a ter maior projeção internacional e a participar mais ativamente das relações políticas europeias por meio da porta de entrada portuguesa (GONÇALVES, 2003). No entanto, a desproporção da distribuição dos benefícios ficou evidente ao longo de sua vigência, com importantes repercussões para a relação do Brasil com o continente africano.

Importante ressaltar em que contexto social o Tratado foi assinado. Na primeira metade do século $X X$, observa-se um grande crescimento da emigração portuguesa para o Brasil, especialmente para o Rio de Janeiro e São Paulo - no período de 1900 a 1980 mais de um milhão de portugueses se estabeleceram no Brasil. A colônia portuguesa, que aqui se instalou, organizou-se em apoio ao governo de Salazar e em defesa da manutenção das colônias na África, exercendo sua pressão sobre a questão até a transferência do Itamaraty do Rio de Janeiro para Brasília, em 1970 (DÁVILA, 2011).

O ideário do lusotropicalismo de Freyre aliado à pressão da comunidade portuguesa no Brasil e da hábil diplomacia portuguesa conseguiu impedir um posicionamento brasileiro que parecia irreversível: o apoio internacional à independência das colônias africanas. Ao mesmo tempo em que o governo de Juscelino Kubistchek representou o ápice do apoio brasileiro a Portugal, com a regulamentação do Tratado de 1953 e o próprio interesse pessoal do presidente no país, também explicitou a discordância de parte da diplomacia brasileira no direcionamento da política externa. Consciente da inevitabilidade dos processos de independência na África e da necessidade de uma posição mais autônoma nos fóruns internacionais, esse grupo mais progressista da diplomacia brasileira convence o presidente Juscelino Kubistchek da necessidade de o Brasil posicionar-se favoravelmente sobre a independência dos países e povos coloniais na XV Assembleia Geral da ONU, em 14 de dezembro de 1960. No entanto, em votação de outra resolução na mesma Assembleia, o Presidente é convencido de que o posicionamento brasileiro em relação à inclusão das províncias ultramarinas de Portugal entre os territórios não autônomos - o que possibilitaria 
a aplicação da Carta da ONU quanto à necessidade de auto-governo desses territórios deveria ser contrário. A partir da XV Assembleia Geral da ONU, o discurso brasileiro passa a ser de defesa da descolonização e reconhecimento da independência das colônias africanas, entretanto, com a permanência do apoio a Portugal e seu colonialismo na África.

Governos Jânio Quadros e João Goulart: aproximação gradual

O posicionamento vacilante da diplomacia brasileira tem seu ponto de inflexão no governo Jânio Quadros, quando demonstrou uma clara inclinação para uma aproximação com os países africanos, dentro dos parâmetros da Política Externa Independente, então em formulação. O discurso realizado por Jânio Quadros, em 15 de março de 1961, foi emblemático para as relações do Brasil com o continente africano ao firmar posição brasileira contrária ao colonialismo e ao racismo, defendendo aspirações comuns com a África, como o desenvolvimento econômico, a defesa pelos preços das matérias-primas, a industrialização e o desejo pela paz (CERVO, 2012; QUADROS, 1961, apud SARAIVA, 2012; LEITE, 2011). As ações empreendidas na curta gestão de Jânio Quadros foram representativas do novo espaço a ser ocupado pela África na PEB, a exemplo da criação da Divisão da África no Itamaraty, das primeiras embaixadas brasileiras em países africanos - Gana ${ }^{1}$, Senegal e Nigéria - e mesmo de programas de concessão de bolsas a estudantes africanos para estudo no Brasil. Entretanto, a política africana de Jânio Quadros e de João Goulart, seu sucessor, foi limitada por algumas questões internas que revelavam algumas inconsistências dessa política.

Dois fatos foram relevantes para caracterizar a inconsistência da Política Externa Independente no tocante à política africana: a manutenção das relações com a África do Sul e do apoio a Portugal na questão da independência das suas colônias na África. Quanto ao primeiro fato, observa-se que, em que pese o discurso brasileiro ser amplamente contrário ao racismo, as relações comerciais do Brasil com o continente africano concentravam-se quase que exclusivamente nas suas relações com a África do Sul, representando cerca de $70 \%$ das exportações brasileiras para o continente em 1962, o que provocou um comportamento

\footnotetext{
${ }_{1}^{1}$ A primeira Embaixada brasileira em um país da África subsaariana foi aberta em Gana, em 1961, sendo Raymundo Souza Dantas o primeiro embaixador em um país africano e também o primeiro embaixador negro do país (DÁVILA, 2011).
} 
silencioso sobre o apartheid sul-africano (SARAIVA, 2012). No que se refere às colônias portuguesas na África, manteve-se a posição de apoio a Portugal.

A política externa defendida pelos governos de Jânio Quadros e João Goulart ordenou-se, além de outros pontos, na reafirmação e fortalecimento dos princípios de nãointervenção e autodeterminação dos povos, com franco apoio à emancipação dos territórios não autônomos (DANTAS, 1962). Apesar de reconhecer a independência de alguns países africanos, instado a opinar sobre o caso de Angola o governo brasileiro absteve-se de votar na Assembleia Geral da ONU de 1961, assumindo posição dúbia sobre a questão.

A crença de que um acordo pacífico era a única forma de preservar os elementos positivos trazidos pela cultura portuguesa às colônias africanas justificavam o entendimento de que caberia a Portugal o reconhecimento do direito do povo angolano à autodeterminação, exortando Portugal a assumir a direção do movimento pela liberdade de Angola. Nesse sentido, o governo brasileiro ofereceu-se para mediar as negociações com as lideranças africanas para a celebração de um calendário que possibilitasse a autonomia progressiva dessas colônias, proposta veemente recusada pelo governo português (DANTAS, 1962; DÁVILA, 2011; MAGALHÃES, 1997). Apesar da manutenção da aliança com o governo português, com a Política Externa Independente, o Brasil experimentou uma reaproximação gradual com o continente que somente foi superada com o rompimento definitivo do Tratado, anos depois.

Os primeiros anos da ditadura militar: completo afastamento

Ao assumir o poder em 1964, o governo militar de Castelo Branco (1964-1967) realinhou a política externa brasileira no sentido de pleno restabelecimento das relações com os Estados Unidos e Portugal, retrocedendo na política de aproximação com o continente africano. Segundo Dávila, o "regime militar virou as costas para a África e intensificou as relações com Portugal justamente no momento em que as guerras contra o domínio português em Angola, Moçambique e Guiné-Bissau passavam a ser uma das preocupações que unia os países africanos independentes" (2011, p.112). Dois fatos foram bastante representativos dessa aproximação e geraram reações das lideranças africanas: a prisão de militantes africanos dos movimentos de libertação em solo brasileiro (especialmente, membros do MPLA de Angola, PAIGC de Guiné-Bissau e Cabo Verde, e da FRELIMO de 
Moçambique), em junho de 1964; e a realização de exercícios navais de um esquadrão naval brasileiro juntamente com portugueses no litoral de Angola.

A prisão de militantes africanos e o fechamento do escritório utilizado pelos movimentos expuseram a atuação, em território brasileiro, de membros da Polícia Internacional e de Defesa do Estado - PIDE do governo português. Após ameaças de deportação para Portugal, os militantes foram libertados e exilados mediante a pressão do embaixador senegalês Henri Senghor e de seu presidente e tio, Léopold Senghor. Registrese que as atuações do presidente e do embaixador Senghor representaram o contrapeso em favor dos movimentos de libertação das colônias africanas no período. Ao apostar que o Brasil poderia exercer um importante papel de negociador na questão da independência das colônias portuguesas, o presidente senegalês realizou uma visita ao Brasil, em setembro de 1964, com o propósito de sensibilizar o governo brasileiro para a descolonização das colônias portuguesas utilizando o argumento de que o Brasil era o exemplo de uma colônia que havia obtido sua independência sem perder sua cultura. Entretanto, sua atuação não foi capaz de provocar a mudança esperada na política externa brasileira, apesar de animar vários debates em torno da questão (DÁVILA, 2011).

Assim, o posicionamento brasileiro significava a manutenção dos laços históricos com Portugal por meio da reafirmação do Tratado de Amizade e Consulta e da celebração de acordos comerciais que se pretendiam ser uma porta de entrada para o continente europeu, até o governo de Ernesto Geisel, quando a PEB rompe, definitivamente, com o colonialismo e com o regime do apartheid sul-africano, buscando estreitar relações econômicas que favorecessem seu projeto de desenvolvimento (MENEZES, 1967; SARAIVA, 2012).

Governos de Emílio Médici e Ernesto Geisel: aproximação pragmática

Os governos de Emílio Médici (1969-1974) e de Ernesto Geisel (1974-1979) podem ser caracterizados, respectivamente, por uma gradual aproximação com os países africanos e pela definitiva ruptura do Tratado de Amizade e Consulta, celebrado com Portugal. Motivados tanto pelo interesse econômico quanto pela pressão internacional, esses governos promoveram uma aproximação até então sem precedentes na diplomacia brasileira.

Diferente dos primeiros governos militares, cuja aliança privilegiada com os Estados Unidos marcou a política externa, no governo Médici, a ausência de recompensas por essa 
aliança já apontava a necessidade de nova direção na política externa que privilegiasse a questão do desenvolvimento em detrimento da segurança. Assim, a orientação política e econômica do governo de Médici passou a ser voltada para a construção do "Brasil potência", que estava alicerçado em planos econômicos - Metas e Bases e I Plano Nacional de Desenvolvimento -, cujos objetivos previam o desenvolvimento acelerado, de forte intervenção estatal, por meio da expansão do mercado interno, modernização do sistema de crédito e estabelecimento de uma nova política de exportação (SOUTO, 2003). Dessa última pauta decorreu uma nova política de diversificação e expansão de mercados, responsável, portanto, pela volta do interesse brasileiro pela África.

Nesse período, como forma de incrementar as relações do Brasil com os países africanos, foi planejada uma viagem do chanceler à época, Mário Gibson Barbosa, que buscou, sobretudo, desconstruir a imagem desfavorável decorrente do posicionamento brasileiro na questão da emancipação das colônias portuguesas. A viagem do chanceler, que durou um mês no ano de 1972, foi bastante representativa da necessidade de uma nova diplomacia que atendesse aos objetivos da política interna. Cada vez mais, ficava claro que a África constituía-se em um mercado promissor para a exportação de produtos industrializados que o Brasil estava produzindo. Nesse sentido, a viagem de Gibson foi

[...] parte de uma estratégia mais ampla para romper a lealdade a Portugal que tinha se consolidado no governo militar, ao mesmo tempo que utilizava as conexões raciais e culturais do Brasil com a África para construir parcerias econômicas e mercados de exportação que iriam sustentar o milagre econômico (DÁVILA, 2011, p.173).

Quando assumiu o cargo de chanceler, Gibson Barbosa propôs uma nova linha de política externa que privilegiasse o aumento da presença brasileira na África atlântica e tentasse reverter o clima de desconfiança e hostilidade que se criou em relação ao Brasil em razão do posicionamento brasileiro na questão da independência das colônias portuguesas. Com esse objetivo, o roteiro estrategicamente preparado teve início na Costa do Marfim e seguiu por Gana, Togo, Benin, Zaire, Gabão, República dos Camarões, Nigéria e Senegal, resultando na assinatura de acordos para cooperação técnica na agricultura, no desenvolvimento de mercados comerciais, na engenharia de infraestrutura, em habitação e em educação. Além da assinatura de acordos, o Itamaraty negociou o restabelecimento da navegação direta entre o Brasil e a África ocidental pela Marinha mercante como forma de 
incrementar as relações comerciais com os países da região, o que, no período da viagem, é exemplificado pela chegada de mercadorias que iam de chuveiros elétricos a geladeiras (DÁVILA, 2011). Nota-se, entretanto, que um posicionamento mais assertivo sobre a questão das colônias portuguesas ainda tardava a acontecer, o que gerava protestos dos países já independentes.

A conjuntura do início do governo Ernesto Geisel foi marcada pelas repercussões geradas pela primeira crise do petróleo de 1973, e pela necessidade de manter os índices favoráveis do "milagre econômico" dos governos anteriores. Para dinamizar a economia brasileira em meio à crise internacional, a opção realizada pelo Governo Geisel foi a de diversificar a estrutura produtiva e modificar a inserção internacional do país pela ótica do comércio exterior. A partir do II Plano Nacional de Desenvolvimento, o governo Geisel buscou tanto modificações na matriz industrial, ampliando a participação da indústria pesada em detrimento da indústria de bens de consumo duráveis, como uma diversificação da matriz enérgica até então dependente do petróleo, com a consequente diversificação de parceiros e de fontes energéticas (CARNEIRO, 2002).

Segundo Sato (1998), a chamada política do "pragmatismo responsável" do presidente Ernesto Geisel tinha conteúdo efetivamente operacional, cujo objetivo foi o de adequar as demandas de uma economia que observou avanços na industrialização, mas que, no entanto, ainda apresentava pontos de vulnerabilidade. Nesse sentido, a compreensão da economia doméstica no período - aliada a outros fatores a serem tratados adiante - pode ser considerada o ponto de partida para a análise da mudança de direcionamento da política externa brasileira para África nesse governo.

A inegável contribuição deixada pela Política Externa Independente dos governos de Jânio Quadros e João Goulart foi melhor experimentada na prática no governo do presidente Geisel. Nota-se, diferentemente, que, no governo Ernesto Geisel, o arrefecimento das relações com a África do Sul tornou-se possível em razão de uma realidade econômica muito mais diversificada na qual se observou grande incremento de relações comerciais com outros países africanos, principalmente com a Nigéria que passou a ser o principal parceiro no continente. O discurso favorável às relações com países africanos ganhou conotação prática com a abertura de novas embaixadas, realização e recebimento de visitas ministeriais e abertura de linhas de crédito, que colocaram na pauta da exportação brasileira uma gama de produtos a um novo conjunto de parceiros. 
À semelhança da política adotada em relação aos países latino-americanos, - Governo concedeu linhas de crédito aos Estados africanos para a aquisição de bens manufaturados e de capital brasileiros. Senegal, Costa do Marfim, Gabão, Níger, Mali e Togo receberam, respectivamente, cerca de US $\$ 13$ milhões, US $\$ 12$ milhões, US $\$ 10$ milhões, US $\$ 1,8$ milhão, US $\$ 690$ mil e US $\$ 690$ mil. Instalaram-se escritórios de representação do Banco do Brasil na Nigéria, na Costa do Marfim, no Senegal e no Gabão, e do Banco Real na Costa do Marfim, sendo este o primeiro banco privado a instalar-se no continente africano. O Banco do Brasil adquiriu $40 \%$ das ações do Banco Internacional da África Ocidental (BIAO), com mais de cem agências no continente (LEITE, 2011, p.144).

Colocando a PEB a serviço do modelo de desenvolvimento de então, a política de aproximação com a África contemplou tanto o incremento do comércio exterior por meio do contato com novos parceiros como buscou novas fontes produtoras de petróleo desvinculadas das questões do Oriente Médio. Assim, a partir de um parque industrial mais complexo, o Brasil passou a exportar cada vez mais produtos manufaturados e importar insumos que garantissem a continuidade do ritmo do crescimento brasileiro. Esse fato, no caso africano, resultou na elevação das exportações brasileiras de US\$190 milhões para US\$600 milhões no período de 1973 a 1979 (LEITE, 2011). Registre-se que subsidiárias da Petrobrás - a Braspetro e a Interbrás - foram utilizadas para desenvolver o comércio com países africanos, principalmente com a Nigéria, como forma de aliviar os déficits na balança de pagamentos por conta da importação de petróleo (DÁVILA, 2011).

Além da mudança do papel da África do Sul no comércio exterior brasileiro, a dinamização da estrutura da ONU, com a entrada de países africanos recém-independentes, exerceu importante papel na luta contra o apartheid e a favor da descolonização. Nesse sentido, além da aprovação de novas resoluções pela Assembleia Geral e pelo Conselho de Segurança, são convocadas a I e ll Conferências Mundiais contra o Racismo e a Discriminação Racial, respectivamente, em 1978 e 1983. A fase de repressão violenta que teve início na década de 1960 e perdurou até a década de 1980 instigou a comunidade internacional, representada pela Organização das Nações Unidas, além de condenar as práticas racistas sulafricanas, a pressionar os Estados e as empresas a cortarem relações com o governo sulafricano (SILVA, 2008, b). Ademais, como lembra Leite (2011), a lista formulada por dezessete países africanos exportadores de petróleo tornou real a ameaça de sanções econômicas em razão do posicionamento brasileiro nas questões da África austral, 
principalmente na questão da descolonização de Angola e Moçambique. Assim, diferente do contexto em que governava Jânio Quadros e João Goulart, o governo Geisel sofreu a pressão de um movimento internacional articulado, principalmente pelos países africanos independentes, pelo rompimento das relações com a África do Sul, sob pena de sofrer sanções e dificultar o desenvolvimento de relações comerciais com os países da região.

O contexto interno português também se revelou favorável a uma tomada de decisão que rompesse com a dubiedade da política externa brasileira. Após mais de quatro décadas de regime fascista, em 1974, o movimento de oficiais portugueses destitui o então presidente Marcello Caetano do poder - a chamada Revolução dos Cravos -, inaugurando uma nova administração inspirada em ideais socialistas que intencionava reconhecer os movimentos de independência das colônias africanas. O período de fragilidade política e econômica por que passava Portugal favoreceu o posicionamento brasileiro de reconhecer a independência das colônias africanas, o que atendia ao interesse nacional e às pressões da comunidade internacional. Assim, diante dos constrangimentos externos e das limitações internas, em 1974, o governo Geisel iniciou o reconhecimento da independência das colônias portuguesas na África. Primeiro, foi reconhecida a independência de Guiné-Bissau, posteriormente Angola, Cabo Verde, São Tomé e Príncipe e Moçambique, rompendo definitivamente com o Tratado de 1953 (LEITE, 2011).

É importante também registrar que, nesse período, as tensões de caráter político, ideológico e militar entre o bloco americano e o soviético se distendiam, dando lugar à intensificação dos debates em torno de questões econômicas entre os hemisférios Norte e Sul. Nesse sentido, a análise do posicionamento brasileiro ante a questão angolana se torna mais interessante quando lembramos a participação de tropas cubanas com apoio e logística soviética na luta pela independência daquele país. Em que pese internamente o governo militar recrudescer a perseguição política a seus opositores e desmontar as organizações de esquerda no país, o governo Geisel ofereceu apoio aos líderes dos movimentos pela independência angolana, instalou uma representação oficial em Luanda, antes mesmo da conclusão das negociações para a independência, e reconheceu ${ }^{2}$ a independência de Angola e a legitimidade do Movimento Popular de Libertação de Angola - MPLA para governar (MAGALHÃES, 1997; SILVA, 2008, a). Mesmo com a adoção de regimes socialistas em

\footnotetext{
${ }^{2} \mathrm{O}$ Brasil é o primeiro país a reconhecer a independência de Angola.
} 
Angola e Moçambique, o governo brasileiro buscou, pragmaticamente, intensificar suas relações comercias, no que resultou em um aumento de US\$5 milhões e US\$6 milhões, em 1974, para US\$89 milhões e US\$17 milhões, em 1979, respectivamente (LEITE, 2011).

Apesar do aumento das relações comerciais entre os países africanos e o Brasil, no caso particular de Moçambique, a demora no reconhecimento da independência das colônias portuguesas e a adoção de um regime socialista geraram prejuízos na relação entre governos desses países e uma relação relativamente próxima entre os africanos e o Partido Comunista Brasileiro - PCB. Antes do reconhecimento oficial da independência de Moçambique, em junho de 1975, o Brasil propôs a criação de uma representação especial em Moçambique assim como em Angola -, proposta esta menosprezada pelo representante da FRELIMO e que, juntamente com a expulsão do cônsul brasileiro pós-independência, demonstrava a hostilidade existente entre os países. A relação que se estabeleceu entre membros do PCB e os governos recém-declarados socialistas no continente, principalmente Angola e Moçambique, parecia mais prestigiada que a própria relação oficial, como implícito no convite de um representante do PCB - Luís Carlos Prestes - e do ex-governador de Pernambuco, Miguel Arraes, para os festejos oficiais da independência moçambicana (CAU, 2011; DÁVILA, 2011).

Note-se que a dinâmica das relações entre o Brasil, Angola e Moçambique diferiram no período pós-independência, o que foi determinante para a inserção de empresas brasileiras ao longo da década de 1980. Para Dávila (2011), a aceitação do apoio brasileiro por Angola e sua rejeição em Moçambique relacionava-se com a disputa interna por poder nesses países: em Angola, o MPLA e os outros movimentos teriam acolhido a representação especial brasileira em razão da condição precária na competição pelo controle do país e a recusa de um aliado externo não geraria benefícios; já em Moçambique, a FRELIMO era um movimento consolidado que não enfrentava oposição em condições de enfrentamento e podia recusar o que o governo brasileiro tinha a oferecer. É certo que ter sido o primeiro país a reconhecer a independência de Angola permitiu ao Brasil ter um status que de longe conseguiria ter em Moçambique. Apesar de, em dezembro de 1975, o Brasil conseguir restabelecer relações oficiais com a criação da embaixada brasileira em território moçambicano, suas atividades não foram capazes de aprofundar as relações da forma desejada.

Pragmaticamente, o governo de Ernesto Geisel tratou de afastar-se de questões ideológicas, resolvendo as questões internacionais a partir dos interesses econômicos 
traçados em seu plano de desenvolvimento. Nesse sentido, o posicionamento da diplomacia brasileira foi o de não se associar ideologicamente a nenhum grupo específico e, nesse sentido, apesar de se solidarizar e ter interesses em comum, não firmou um alinhamento com grupos de países em desenvolvimento. Não era interesse brasileiro associar-se à ideia de atraso, mas, ao mesmo tempo, a participação e o apoio a ações que tratassem de regras de comércio exterior favoráveis aos países subdesenvolvidos e o estabelecimento de um novo equilíbrio de poder eram desejadas pelo governo.

Período democrático: afastamento

Nas décadas seguintes, a crise econômica e as guerras civis em que sucumbiu grande parte dos países africanos impediram o aprofundamento das relações com o continente e até mesmo resultaram em um considerável afastamento a partir da década de 1980. Tanto a redução dos níveis de comércio do Brasil com a África, que retrocederam aos índices da década de 1950 - correspondente a 2\% das relações comerciais do Brasil e centrada, novamente, na África do Sul - como a proposta de redução das embaixadas brasileiras no governo Itamar Franco (1992-1994), evidenciava essa tendência de afastamento (SARAIVA, 2012). Nesse período, destacaram-se apenas algumas ações, como a participação em missões de paz em Moçambique (1994) e Angola (1995) e a criação da Comunidade dos Países de Língua Portuguesa - CPLP, no governo de Fernando Henrique Cardoso (1995-2002), com o objetivo de relacionar o país com os assuntos africanos. Dessas iniciativas, a que mais gerou expectativas quanto a uma reaproximação com os africanos foi, sem dúvida, a criação da CPLP.

Após um controverso e demorado processo de negociação que se iniciou no governo de José Sarney, em 1989, a proposta de criação da CPLP somente foi oficializada em 17 de julho de 1996, no governo de Fernando Henrique Cardoso. Desde sua origem, a organização privilegia as vertentes da concertação político-diplomática entre seus membros, a cooperação em todos os domínios e a promoção e difusão da língua portuguesa, designadamente por meio do Instituto Internacional da Língua Portuguesa. Importante ressaltar que, quanto a uma possível vertente econômico-comercial, documento elaborado pela Embaixada brasileira em Lisboa já aponta que a organização não nasce com o objetivo de implantar uma zona de livre comércio ou mercado comum, principalmente em razão das 
dificuldades geradas pela sua descontinuidade geográfica, mas se restringiria a propósitos comunitários, como incentivo a múltiplas formas de associação empresarial e intercâmbio de opiniões e conhecimento (EMBAIXADA DO BRASIL EM LISBOA, 1994; LOPES; SANTOS, 2006).

Importa, aqui, questionar o impacto dessa organização na relação do Brasil com os países africanos. A proposta de criação da CPLP ocorreu em um momento em que as relações do Brasil com o continente africano experimentavam um profundo afastamento. Nesse sentido, o período pós-abertura democrática pode ser caracterizado, no âmbito da política externa, pela intensificação da participação em foros multilaterais e pelos processos de integração regional, entretanto, sem deixar de privilegiar as relações econômicas com os Estados Unidos e países europeus. Foi nesse contexto que a criação de tal entidade, além de ser uma resposta aos constrangimentos que remontam à ideia de fundação de uma Comunidade Luso-Brasileira já na primeira metade do século $X X$, supre, pela via multilateral, uma lacuna na relação com o continente.

Entretanto, a participação ativa do Brasil na concepção e formalização da CPLP não significou plena adesão à ideia de aproximação com a África. Ao longo dos governos dos presidentes José Sarney, Fernando Collor, Itamar Franco e Fernando Henrique Cardoso, pouco se avançou na intensificação das relações econômicas e mesmo algumas embaixadas no continente foram fechadas. Nesse sentido, muitas críticas têm sido feitas quanto à participação brasileira, como expõe a diplomata portuguesa Maria Regina Marcheta:

Nesse contexto, só Brasil parece manter uma dupla apreciação desse projecto, oscilando entre uma adesão entusiástica e algum sentimento de reserva, fruto da própria ambivalência política com que encara o relacionamento com Portugal e o seu próprio posicionamento no mundo. $\mathrm{A}$ política brasileira relativamente à CPLP, contraditória e ambivalente, tem contribuído para o estado de quase letargia da organização, ao mesmo tempo que reflecte as dissidências políticas internas, entre uma classe política defensora da linha cultural e romântica da lusofonia (José Sarney, Itamar Franco, José Aparecido de Oliveira) e uma outra mais pragmática e mercantilista (Fernando Henrique Cardoso e José Lampreia) (MARCHUETA, 2003, p.128).

Essas críticas, no entanto, exigem uma nova contextualização com a chegada do presidente Lula da Silva ao governo. Como será visto a seguir, nesse governo, observou-se uma reaproximação com países africanos, consistente, em grande parte, em uma crescente 
cooperação bilateral, negociada diretamente com os países ao invés da mediação realizada pela entidade.

É certo que a mera participação na CPLP, principalmente ao longo da década de 1990, não foi capaz de reestabelecer as relações havidas na década de 1970. Apesar das expectativas criadas, os problemas internos vividos pelos países têm dificultado maior estabilidade nas relações políticas e econômicas dentro da Comunidade.

Governo Lula da Silva: reaproximação

Assim como anteriormente a pauta africana surgiu na política externa brasileira em momentos de políticas desenvolvimentistas, o governo de Lula da Silva incorporou essa pauta e intensificou as relações com os países africanos ao longo do seu governo em momento de estratégico crescimento econômico. Se durante o governo de FHC o modelo neoliberal adotado preconizou a redução das atividades do Estado na economia (com programas de privatizações de empresas estatais) e medidas de estabilização baseadas no controle da inflação, câmbio e superávit, o governo Lula buscou criar uma agenda que aliasse estabilidade econômica e desenvolvimento, o que teve importantes implicações para o direcionamento da política externa brasileira.

A eleição do presidente Lula da Silva, em 2003, foi precedida pela insatisfação de diversos setores da sociedade brasileira quanto aos rumos da política neoliberal, cujos efeitos eram sentidos nas camadas mais populares ao grande empresariado. Reivindicava-se, nesse sentido, uma política que ultrapassasse a estabilização e o ajuste fiscal e incluísse novas prioridades, como o crescimento econômico e geração de emprego associados à formulação de uma nova estratégia de inserção internacional (DINIZ; BOSCHI, 2007). A garantia dada pelo candidato Lula da Silva de que as medidas de estabilização econômica continuariam a ser realizadas e os contratos respeitados, mas, no entanto, com o incremento de ações voltadas ao desenvolvimento - expressa na sua "Carta ao povo brasileiro" -, atraiu para sua órbita importantes nomes do empresariado brasileiro que passaram a apoiar abertamente sua candidatura (DINIZ; BOSCHI, 2007).

No campo da política externa, o programa proposto pela coalização encabeçada pelo Partido dos Trabalhadores-PT previa uma atuação mais assertiva, na qual a associação da política externa como meio para implantação de uma política de desenvolvimento nacional 
foi claramente estabelecida. Destacam-se no programa, além da questão do desenvolvimento, os fatores: integração regional no âmbito da América do Sul; reconstrução do MERCOSUL; negociação relacionada às medidas protecionistas dos EUA para a criação da ALCA; estabelecimento de relações equilibradas com os países desenvolvidos e aproximação com países de importância regional, como África do Sul, Índia, China e Rússia, e também do continente africano de modo geral, que possibilitem construir relações mais democráticas nos organismos multilaterais; esforço exportador, com investimento em tecnologia; e desenvolvimento da indústria hoteleira com atração de investimentos estrangeiros (PROGRAMA ..., 2002).

No primeiro mandato (2003-2006), observou-se mais continuidade na condução da política macroeconômica do que reformas substanciais que atendessem aos reclames por desenvolvimento. No entanto, ao longo dos dois mandatos, ficou evidente sua política de manutenção da estabilidade e expansão do mercado interno, capitaneado pelos investimentos em programas de transferência de renda, pelo aumento real do salário mínimo e pelo aumento de crédito, caracterizando-se o Estado como o grande indutor do crescimento, condição esta visibilizada pelo Programa de Aceleração do Crescimento - PAC, em 2007 (FONSECA et al, 2012; SINGER, 2012). Seguindo as diretrizes de uma política macroeconômica voltada para o desenvolvimento nacional, a diplomacia brasileira, dirigida pelo chanceler Celso Amorim e assessorada por Marco Aurélio Garcia, manteve sua posição de negociar nos foros multilaterais questões relacionadas à proteção e expansão das relações comerciais, mas, sobretudo, buscou novas coalizões, principalmente com países do hemisfério Sul, como estratégia para barganhar melhores condições na economia internacional. Instâncias como o Fórum Índia, Brasil e África do Sul -IBAS e o Fórum Brasil, Rússia, Índia, China e África do Sul - BRICS, apesar de não apresentarem uma clara agenda comum, buscou agregar importantes países em torno da necessidade de construção de uma nova arquitetura internacional na área econômico-financeira, especialmente aprofundada com a criação do Banco BRICS no governo Dilma Rousseff.

Se o governo de Fernando Henrique Cardoso poderia ser caracterizado por sua estratégia de credibilidade, o governo Lula da Silva seria caracterizado pela autonomia nas relações internacionais (LIMA, 2005). Esse posicionamento da diplomacia brasileira, chamada por Tullo Vigevani e Gabiel Cepaluni (2007) de "autonomia pela diversificação", enfatizou a necessidade de cooperação entre os países do Sul como forma de atingir maior 
equilíbrio com os países do Norte, realizando ajustes, aumentando o protagonismo internacional do país e consolidando mudanças de programa na política externa. Ao partir de uma postura mais autonomista nas relações internacionais, o governo Lula da Silva buscou estreitar relações com países da América do Sul - com a tentativa de reformas no MERCOSUL, sobretudo, no primeiro mandato, e com a criação da UNASUL, em 2008 -, e da África, resultando em um aumento dos acordos, principalmente, de cooperação técnica e dos fluxos comerciais entre os países do eixo. É bastante representativa a inversão da posição brasileira quando os valores doados à cooperação ultrapassam os recebidos em $2010^{3}$.

No caso particular da inclusão da pauta africana na PEB do governo Lula da Silva é preciso tecer algumas considerações. É importante lembrar, primeiramente, que essa pauta não foi forjada no seio do Partido dos Trabalhadores, apesar de ser amplamente contaminada pela ideia de solidariedade entre os povos explorados pelo capitalismo - como demonstra seu Manifesto de Fundação: "[...] O PT manifesta sua solidariedade à luta de todas as massas oprimidas do mundo". Os documentos oficiais do PT eram omissos quanto aos temas africanos, havendo clara priorização para ações de aproximação com países sulamericanos. Ressalta Beluce Belluci, ex-cooperante brasileiro em Moçambique, que os "petistas que viveram na África praticamente não chegaram a estabelecer um diálogo com a militância negra do PT, quer sobre o continente africano quer sobre as propostas para as relações entre o Brasil e a África" (2010, p.17). Apenas às vésperas da campanha eleitoral de 2002, a ideia de construção de uma política externa para a África, de forma menos idealizada, foi incorporada e, posteriormente, assumida pelo Partido por meio de uma Resolução da Secretaria de Assuntos Internacionais, no $3^{\circ}$ Congresso do PT, em 2007. Assim, mais do que um tema elaborado dentro do PT, a política para a África foi pensada a partir do conjunto de interesses que passaram a compor o governo, apesar de influenciado pelos princípios que norteiam o Partido.

Influenciado pela ideia de solidariedade, o discurso de aproximação com o continente africano passou a ser propagado a partir da valorização do princípio da cooperação, principalmente, e da necessidade de reestabelecer relações comerciais com esses países. No

\footnotetext{
3 Segundo sítio oficial da Organização para a Cooperação e Desenvolvimento Econômico - OCDE, o total líquido de ajuda desembolsado pela organização ao Brasil foi de US\$403.22 milhões em 2010, enquanto os gastos da cooperação realizada pelo Brasil com paises em desenvolvimento perfez o total aproximado de US\$923 milhões no mesmo ano (IPEA; $A B C, 2013 ; O C D E$, 2015).
} 
seu discurso de posse, em $1^{\circ}$ de janeiro de 2003, o Ministro Celso Amorim declara, apesar de afirmar que a América do Sul é prioridade da política externa brasileira, que:

[...] Desenvolveremos, inclusive por meio de parcerias com outros países e organizações, maior cooperação com os países africanos. Angola e Moçambique, que passaram por prolongados conflitos internos, receberão atenção especial. Valorizaremos a cooperação no âmbito da Comunidade dos Países de Língua Portuguesa (CPLP) [...] (AMORIM, 2003, p.57).

Na prática, a reaproximação do Brasil traduziu-se em uma diplomacia presidencial atuante, no aumento do número de embaixadas, no aumento dos acordos de cooperação técnica e, principalmente, no aumento do fluxo comercial com o continente. Nos dois mandatos, o Presidente Lula realizou 11 viagens ao continente, visitando 28 países (MRE, 2011), cujos desdobramentos exigiram uma maior atuação da diplomacia do Itamaraty, como relata o Ministro Celso Amorim, em seu discurso de transmissão do cargo em 2011, ao dizer que esteve em São Tomé e Príncipe tanto quanto em Washington. Foram abertas 17 embaixadas, sendo 11 delas já no primeiro mandato - Etiópia, Sudão, Benin, Tanzânia, Camarões, Togo, Guiné Equatorial, São Tomé e Príncipe, Guiné, Botsuana e Zâmbia ( $A B C$, 2010; LEITE, 2011).

Como resultado das primeiras visitas oficiais, o governo brasileiro se disponibilizou a realizar vários projetos de cooperação para o desenvolvimento, destacando-se o compromisso de construir uma fábrica de medicamentos antirretrovirais para combate ao HIV/AIDS no continente, em cooperação com o governo moçambicano. O discurso brasileiro para a cooperação na África, no entanto, além dos elementos que marcam a ideia da Cooperação Sul-Sul, traz em seu bojo outros elementos que buscam qualificá-lo. Ao menos no discurso, a cooperação brasileira buscou desvincular-se dos interesses econômicos no continente, aliando um discurso moral de cumprimento de dívida histórica com os países africanos, como é explicitado por Fonseca: "[...] los valores más altos de éstos no se encuentran em nustros vecinos, y sí em África, continente con el cual tenemos deudas históricas por su valiosa contribución a lo que es hoy dia la multiétnica nación brasileña" (2010, p.67).

Nota-se, apesar da aproximação com a África estar pautada na retórica da solidariedade cooperante, a política externa para o continente não esteve descolada do projeto de desenvolvimento nacional idealizado pelo governo petista. Nesse sentido, uma pauta foi particularmente interessante para compreender a profundidade dessas relações - 
o comércio de produtos e serviços. Desde o início do seu primeiro mandato, apesar do incipiente comércio com a maioria dos países da África subsaariana, o crescimento econômico experimentado por alguns desses países, impulsionado pelo aumento do valor das commodities ao longo da década de 2000 , fez com que o governo brasileiro realizasse um esforço de prospecção de oportunidades no continente. O "efeito China" fornecia o contexto favorável tanto para o interesse brasileiro de incrementar as exportações brasileiras de commodities, principalmente soja, como para explorar oportunidades em países que passaram a crescer com a exportação de seus recursos naturais, como carvão, gás natural e petróleo. Em sua primeira viagem como chanceler ao continente, em maio de 2003, o Ministro Celso Amorim ressaltou as perspectivas promissoras para o redimensionamento das relações políticas e econômico-comerciais, com a participação de grandes empresas brasileiras em importantes investimentos, como o interesse moçambicano em contar com a participação brasileira no projeto de exploração de carvão de Moatize (AMORIM, 2011). Com o mesmo intuito, as viagens presidenciais contaram em sua comitiva com a presença de empresários interessados em investir no continente, realizando-se eventos empresariais paralelos.

Registre-se que, desde o final da década de 1990, como sinal de desejo do reestabelecimento das relações comerciais com o continente, alguns países africanos receberam o perdão por dívidas contraídas ao longo das décadas de 1970 e 1980, principalmente junto ao Banco do Brasil. O perdão da dívida estava inserido em um movimento internacional de alívio da carga da dívida para a economia dos países pobres muito endividados - PPME, com o objetivo de aumentar a liquidez de suas economias. 
TABELA 1 - Série Histórica da balança comercial do Brasil-África no período de $2000-2016$ (em US\$F.O.B)

\begin{tabular}{|c|c|c|c|c|}
\hline & \multirow{2}{*}{\begin{tabular}{|l} 
EXPORTAÇÃO \\
US\$ FOB (A) \\
\end{tabular}} & \multirow{2}{*}{$\begin{array}{l}\text { IMPORTAÇÃO } \\
\text { US\$ FOB (B) } \\
\end{array}$} & \multicolumn{2}{|c|}{ RESULTADO } \\
\hline & & & SALDO (A-B) & CORRENTE $(A+B)$ \\
\hline 2000 & 1.347 .098 .183 & 2.907 .082 .676 & -1.559 .984 .493 & 4.254 .180 .859 \\
\hline 2001 & 1.989 .031 .346 & 3.330 .949 .802 & -1.341 .918 .456 & 5.319 .981 .148 \\
\hline 2002 & 2.363 .340 .654 & 2.675 .612 .821 & -312.272 .167 & 5.038 .953 .475 \\
\hline 2003 & 2.862 .003 .914 & 3.291 .174 .938 & -429.171 .024 & 6.153 .178 .852 \\
\hline 2004 & 4.247 .699 .268 & 6.183 .472 .779 & -1.935 .773 .511 & 10.431 .172 .047 \\
\hline 2005 & 5.981 .353 .507 & 6.656 .664 .579 & $-675 \cdot 311.072$ & 12.638 .018 .086 \\
\hline 2006 & $7 \cdot 455.879 \cdot 389$ & 8.110 .811 .144 & -654.931 .755 & 15.566 .690 .533 \\
\hline 2007 & 8.578 .221 .741 & 11.346 .724 .972 & -2.768 .503 .231 & 19.924 .946 .713 \\
\hline 2008 & $10.169 \cdot 567.120$ & 15.761 .124 .122 & -5.591 .557 .002 & 25.930 .691 .242 \\
\hline 2009 & 8.692 .380 .077 & 8.465 .581 .857 & 226.798 .220 & 17.157 .961 .934 \\
\hline 2010 & 9.261 .599 .799 & 11.297 .251 .661 & -2.035 .651 .862 & $20.55^{8} .851 .460$ \\
\hline 2011 & 12.224 .792 .600 & 15.436 .247 .556 & -3.211 .454 .956 & 27.661 .040 .156 \\
\hline 2012 & 12.212 .624 .157 & 14.266 .074 .678 & -2.053 .450 .521 & 26.478 .698 .835 \\
\hline 2013 & 11.087 .040 .582 & 17.446 .394 .849 & -6.359 .354 .267 & 28.533 .435 .431 \\
\hline 2014 & 9.701 .013 .694 & 17.060 .825 .603 & -7.359 .811 .909 & 26.761 .839 .297 \\
\hline 2015 & 8.202 .082 .594 & 8.763 .918 .378 & -561.835 .784 & 16.966 .000 .972 \\
\hline 2016 & 7.832 .441 .537 & 4.601 .075 .030 & 3.231 .366 .507 & 12.433 .516 .567 \\
\hline
\end{tabular}

Fonte: Extraído do sítio eletrônico do Ministério da Indústria e Comércio Exterior, disponível em $<$ http://www.mdic.gov.br/comercio-exterior/estatisticas-de-comercio-exterior/balanca-comercial-brasileiramensal-2>. Acessado em: 10 abr. 2017.

A complexificação da economia brasileira desde a segunda metade do século $X X$ e, por outro lado, as condições favoráveis na África - estabilização política, fim do apartheid na África do Sul, criação de iniciativas de integração, como a União Africana e a Comunidade para o Desenvolvimento da África Austral - favoreceram a intensificação das relações comerciais a partir de uma gama mais variada de produtos e serviços a um maior número de países. Por um lado, os principais produtos de exportação brasileiros no continente foram açúcares, carnes e minério de ferro, com destaque para o aumento da exportação de produtos industrializados. Por outro lado, os principais produtos importados foram o petróleo (grande responsável pelo saldo negativo na balança comercial brasileira no continente), produtos químicos, cacau e pedras preciosas (LEITE, 2011; MDIC, 2017). Registre-se que importante reflexo desse aumento de transações comerciais foi a reabertura de uma agência do Banco do Brasil em Angola, em 2005, após reivindicação de empresários brasileiros (MOURÃO et al, 2006). 
Importante destacar que, apesar do saldo da balança comercial com o continente ser negativa, a dinâmica comercial com cada país africano pode apresentar grandes variações. Alguns países apresentam maior estabilidade nas relações comerciais, como o comércio com a África do Sul, entretanto, a relação comercial com países como Moçambique, apesar do saldo positivo, apresenta grande variação quantitativa tanto nas exportações como importações, o que assinala certa fragilidade dessas relações comerciais (MINISTÉRIO DO DESENVOLVIMENTO, INDÚSTRIA E COMÉRCIO, 2017).

Ressalte-se que duas agências governamentais tiveram papel fundamental no incremento das relações comerciais na África: a Agência Brasileira de Promoção de Exportações e Investimentos - APEX e o Banco Nacional de Desenvolvimento Econômico e Social - BNDES. A APEX, criada em maio de 2003 para promover produtos e serviços brasileiros no exterior e atrair investimentos estrangeiros para setores estratégicos da economia brasileira, tem como atividades principais na África a realização de missões de prospecção e comerciais, além de promover eventos de valorização dos produtos e serviços brasileiros. A partir dessas missões, foram identificados os países com maior potencial para vendas externas brasileiras, destacando-se África do Sul, Angola e Moçambique na África subsaariana. Também foram elaborados estudos traçando o perfil do mercado e as oportunidades para empresários brasileiros (APEX, 2011).

Da mesma forma, tanto no que se refere ao atendimento do mercado externo via exportações como por investimento direto no exterior, o BNDES tem tido um papel destacado na promoção do processo de internacionalização das empresas brasileiras. Motivado pela necessidade de acesso a novos mercados e recursos diante da pressão competitiva internacional, uma política de internacionalização de empresas brasileiras passou a ser estimulada sob a justificativa de que não somente as empresas seriam beneficiadas, mas haveria ganhos para o país a partir do aumento das exportações, geração de divisas (repatriação dos lucros) e acesso a novas tecnologias. Além da concessão de créditos para empresas brasileiras exportadoras de bens e serviços, uma reformulação no Estatuto do Banco, em 2007, possibilitou o financiamento para empresas brasileiras adquirirem ativos e realizarem investimentos no exterior, desde que estes contribuam para o desenvolvimento econômico e social nacional (BNDES, 2014). Somente no ano de 2009, a concessão de créditos do BNDES para projetos na África chegou a US\$766 milhões, 
representando o total de $36 \%$ dos desembolsos em financiamento internacional do Banco (GARCIA; KATO; FONTES, 2012).

Apesar de contar com a participação de empresas dos ramos alimentício e agronegócio, o investimento direto no exterior tem-se centrado em empresas de: exploração de recursos naturais e primários, como a Companhia Vale do Rio Doce e a Petrobras; em siderúrgicas, como Metalúrgica Gerdau e Companhia Siderúrgica Nacional; manufatureiras, como a Embraer; e construtoras, como Odebrecht e Camargo Correa (GARCIA, 2009). Campos (2009) ressalta que a história da expansão dessas empresas foi grandemente estimulada pela demanda estatal nacional por serviços de infraestrutura já nas décadas de 1950 e 1960, em razão da construção de usinas hidrelétricas, barragens, rodovias e prestação de serviços na órbita da Superintendência do Desenvolvimento do Nordeste - SUDENE, da Petrobras e, por último, do Banco Nacional de Habitação. Já no final da década de 1970, essas empresas tinham capital acumulado e tecnologia suficiente para se organizar e pressionar o aparelho estatal por políticas mais favoráveis e iniciar processos de internacionalização (CAMPOS, 2009).

A inexistência de empresas locais competitivas facilitou a entrada dessas mesmas empresas brasileiras no mercado latino-americano, principalmente a Bolívia, africano e, em menor escala, no mercado do Oriente Médio. Nesse sentido, Campos destaca a importância da experiência na África para as empresas e a importância do Estado nesse processo:

O continente africano apresenta exatamente essas características e, por isso, é o segundo mercado preferencial para as construtoras brasileiras, destacando-se a África portuguesa. Após a independência desses países, muitas obras foram encomendadas a empresas estrangeiras pagas com recursos da exportação de matérias-primas e recursos minerais. O caso de Angola é emblemático. Independente em 1975, o país de governo comunista teve como primeiro país estrangeiro a reconhecer a sua independência o Brasil, que tinha então um Estado ditatorial de direita. Logo em seguida, a Petrobras passou a atuar no país e, já em 1980, também a Odebrecht, para construir hidrelétricas, estradas e sistemas de abastecimento de água. Hoje, a empreiteira tem quase 11 mil funcionários no país e divide o mercado de engenharia local com AG, CC e QG.

[...]

Para que o sucesso dessas incursões no estrangeiro tenha ocorrido, não se pode deixar de lembrar a importância central que teve o Estado brasileiro. Se foi com grandes obras de infraestrutura realizadas pelo Estado e política habitacional favorável que as companhias brasileiras de engenharia se fortaleceram - criando um oligopólio no mercado de construção pesada -, as políticas estatais foram fundamentais para a internacionalização dessas 
empresas. Através de políticas externas favoráveis, convites para projetos internacionais e financiamento direto, o Estado brasileiro foi decisivo para o processo de transnacionalização. Também para a ramificação das empresas, o aparelho de Estado teve papel essencial pelas privatizações realizadas e pela criação dos mercados de concessão rodoviária, de energia e outros (CAMPOS, 2009, p.109 e 114).

$\mathrm{Na}$ esteira do aumento de incentivos à internacionalização, o BNDES implementou um modelo de financiamento à exportação baseado na experiência com Angola, que previa a concessão de créditos para a exportação de bens e serviços brasileiros para obras de infraestrutura tendo como garantias recebíveis o petróleo. O crédito é cedido diretamente ao importador, no caso Angola, que se compromete a manter um determinado saldo em conta-garantia do Banco do Brasil equivalente ao valor fixado em barris de petróleo. $\mathrm{O}$ BNDES projetou replicar a experiência angolana em Moçambique, utilizando parte dos royalties pagos pela Vale ao governo moçambicano pela exploração do carvão de Moatize como garantia de futuros financiamentos (VALOR ECONÔMICO, 2012). Importante ressaltar que, já na primeira visita a Moçambique, por ocasião do encerramento do seminário "BrasilMoçambique: comércio e investimentos", em 05 de novembro de 2003, o presidente Lula da Silva afirmou a necessidade de projetos de grande envergadura no país:

Necessitamos, também, de projetos de grande envergadura, que sirvam de âncora ao nosso relacionamento econômico. Por isso tenho procurado apoiar o interesse de algumas empresas e, sobretudo, da Vale do Rio Doce na exploração de carvão de Moatize.

$[\ldots]$

Todos esses projetos supõem acesso a crédito. O Banco Nacional de Desenvolvimento Econômico e Social-BNDES está procurando viabilizar linhas de crédito para financiar o comércio e os investimentos de empresas brasileiras em países africanos. Moçambique ocupará um lugar prioritário nesta iniciativa (2003, p.2-3).

Apesar de muitos desdobramentos dos negócios extrapolarem o governo Lula da Silva, o mais significativo investimento brasileiro no exterior - o projeto carvão de Moatize da Companhia Vale do Rio Doce, por meio de sua subsidiária Rio Doce Moçambique - foi celebrado em 2007, com investimento total equivalente a US\$1.535.011.000,00, segundo o Centro de Promoção de Investimentos de Moçambique. Apesar da importância desse projeto para a economia moçambicana, muitos conflitos têm decorrido de sua execução. Por exemplo, a necessidade de reassentamento de centenas de famílias, que denunciaram o 
descumprimento das promessas da Vale quanto ao pagamento de indenizações, assim como a baixa qualidade das edificações construídas nos assentamentos, a falta de acesso à água potável, terra arável, energia e transporte (MOSCA; SELEMANE, 2012). Além desses fatores, muitas organizações não governamentais questionam a falta de transparência dos contratos mineiros, especialmente os relacionados aos megaprojetos, cujos valores atribuídos ao Estado moçambicano são desconhecidos pela própria sociedade local.

Juntamente ao estímulo da internacionalização da exportação de bens e serviços por empresas privadas brasileiras, a participação de capital nacional em investimentos no exterior também é notada, inclusive de capital estatal. Ressalte-se que a intensificação da financeirização do capital e dos processos de fusões de empresas fomentou a formação de grandes conglomerados com capitais de diversas procedências, o que dificulta o mapeamento dos investimentos brasileiros no exterior.

Algumas críticas foram formuladas à política externa de aproximação com a África, baseadas, principalmente, no entendimento que esse comércio é pouco relevante e não compensador em face das perdas das exportações brasileiras para os países do Norte. Para os críticos, o esforço de aproximação seria promovido em bases menos pragmáticas do que ideológicas, tendo em vista que esses países pouco teriam a oferecer em termos de mercado consumidor e investimentos. Entretanto, esclarece o Itamaraty que os novos fluxos comerciais com a África são complementares e têm um tempo próprio de maturação (LEITE, 2011; MOURÃO et al, 2006). Havia, portanto, uma expectativa favorável do incremento das exportações brasileiras para o continente africano.

Governo Dilma Rousseff: desestímulo gradual

Diferente do presidente Lula da Silva, a presidenta Dilma Rousseff se voltou para as questões domésticas, deixando a política internacional em posição de menor protagonismo. Nessa conjuntura, alguns fatos evidenciam o retrocesso que a política africanista passou a experimentar no período. No período de cinco anos de mandato, foram realizadas apenas três viagens ao continente africano - em 2011, para a África do Sul, Moçambique e Angola e, em 2013 (nos meses de fevereiro e março), para Guiné Equatorial, Nigéria e África do Sul. Com exceção das visitas à Moçambique, Angola e Nigéria, as viagens estavam associadas à 
realização de encontros de Cúpula como o Fórum de Diálogo Índia-Brasil-África do Sul/IBAS, a Cúpula América do Sul-África e o encontro do BRICS.

Apesar de uma postura de menor esforço na aproximação com os países africanos, o último relatório elaborado pelo Instituto de Pesquisas Econômicas Aplicadas -IPEA, em parceria com a Agência Brasileira de Cooperação - ABC, revela que, ao menos nos três primeiros anos de mandato (2011-2013), os valores investidos na cooperação mantiveram-se em patamares próximos ou superiores aos anos anteriores, destacando-se a África como grande receptor da cooperação técnica, liderado por Moçambique. Ressalte-se que inexistem relatórios dos anos posteriores que atestem uma tendência de queda dos valores da cooperação, entretanto, uma mudança no discurso da presidenta Dilma explicitou uma outra concepção de cooperação que se distanciava da construção do discurso da solidariedade SulSul apregoado pelo presidente Lula. Em viagem à Etiópia, por ocasião dos eventos comemorativos do cinquentenário da União Africana, em maio de 2013, a Presidenta Dilma Rousseff evidenciou a intenção de realizar mudanças estruturais na $A B C$, criando uma nova agência que aliasse a viabilização de investimentos e a cooperação técnica conjuntamente. Nota-se, no entanto, que a proposta contou com rejeição dentro da própria $A B C$ e não se registrou nenhum movimento efetivo para sua operacionalização.

Da mesma forma, os dados da corrente de comércio entre o Brasil e os países africanos mantiveram-se em padrão elevado até 2015, quando começa a decrescer acentuadamente. Este decréscimo pode ser parcialmente atribuído a uma política que reduziu os estímulos para a atividade econômica entre esses países - inclusive com redução das linhas de crédito disponibilizadas anteriormente pelo BNDES -, mas, em grande, decorreu da queda do preço internacional do petróleo, principal produto importado do continente africano pelo Brasil, que em janeiro de 2016 chegou a US\$29,924 por barril, representando uma queda aproximada de $68 \%$ em relação a janeiro de 2011 , no valor de US\$92,66. Na outra ponta, dos investimentos diretos no exterior, as principais empresas brasileiras, notadamente do setor de infraestrutura, têm sido abaladas pelas investigações da Operação Lava-Jato, dificultando não somente sua capacidade de investimento no exterior, mas tendo também suas operações no exterior investigadas, como o caso das operações da Odebrecht em Angola.

\footnotetext{
4 Informação obtida em <http://www.indexmundi.com/pt/pre\%E7os-de-

mercado/?mercadoria=petr\% $\mathrm{C}_{3} \%$ B3leo-bruto\&meses=300>. Acesso em 14 abr. 2017.
} 


\section{Considerações finais}

Diferente do que pode ser a ideia corrente na sociedade brasileira, a "natural" aproximação do Brasil com os países africanos não se tem realizado como imaginado, caracterizando-se, ao longo do tempo, por sua fragilidade e pouco aprofundamento. Desde o período do domínio colonial no continente africano, muitos fatores têm dificultado essa aproximação, fatores que associam as realidades internas de cada país e o contexto internacional. O pós-independência, em muitos países africanos, ficou marcado pela disputa de poder por diversos grupos (em geral, marcados por diferenças étnicas ou por diferentes adesões ideológicas dentro do contexto da Guerra Fria), que culminou com a guerra civil em muitos deles. A instabilidade gerada pela guerra foi um grande fator dificultador dessas relações, considerando a precarização dos fluxos de pessoas e mercadorias; entretanto, as dificuldades no desenvolvimento das relações com o continente africano foram potencializadas por políticas que apregoavam sua insignificância.

Desconsiderando o afastamento por certa vinculação ideológica ao colonialismo português em momentos anteriores à independência, a tendência brasileira tem sido de distanciar-se do continente em momentos de crise econômica. Por não constituírem economias complementares, mas, ao contrário, concorrerem no mercado internacional como países exportadores de commodities, em momentos de crise econômica o governo brasileiro, recorrentemente, volta-se para os mercados norte-americano e europeu como única alternativa para manutenção de seu volume de exportações. Se ao longo do governo Geisel houve um esforço para a conquista de mercado consumidor africano para os produtos brasileiros industrializados, esse mercado é hoje, em grande parte, ocupado por produtos chineses e sul-africanos. Assim, se havia uma expectativa de abertura de mercado, as ausências de políticas de estímulo resultaram na sua perda, cabendo ao Brasil sua consolidação no mercado consumidor de produtos alimentares e de origem animal. Por outro lado, a economia africana pouco se dinamizou, mantendo-se como grande exportadora de derivados do petróleo, fator esse responsável pelo saldo negativo da balança comercial do Brasil com o continente.

Importa registrar, como reflexo da fragilidade das relações nos níveis político e econômico, a dificuldade de maior fluxo de pessoas entre o Brasil e os países africanos. Apesar das facilidades de comunicação e transporte sem precedentes, o Brasil conta com 
apenas três aeroportos que fazem transporte direto ao continente - o aeroporto de Recife e Fortaleza, que operam voos por meio da Cabo Verde Airlines/TACV, e o aeroporto de Guarulhos em São Paulo, da onde saem a grande parte dos voos por meio de empresas brasileiras (LATAM e Avianca) e africanas (South African Airways e Ethiopian Airlines). Registre-se que muitas empresas europeias realizam o transporte para o continente, entretanto, com conexão em países europeus.

Nota-se que, no governo de Lula da Silva, sua política buscava seguir o caminho inverso, criando alternativas a partir de novos parceiros e com um discurso revigorado. A incorporação do princípio de uma solidariedade do Sul e da ideia da existência de uma dívida histórica com o continente proporcionou uma maior interlocução com os representantes africanos, considerando que a relação se tornou mais ampliada e menos pragmática. Apesar da importância das relações econômicas, exemplificada pelos grandes investimentos brasileiros e considerável aumento das trocas comerciais no período, a realização de projetos de cooperação técnica passou a ser um importante instrumento da política externa. Em que pese as críticas sobre o conteúdo de alguns desses projetos - especialmente, o ProSavana -, a nova política africanista proposta no governo Lula possibilitou a realização de importantes ações, como a construção da fábrica de medicamentos antirretrovirais em Moçambique e a intensificação da cooperação na área educacional, que, inclusive, teve como desdobramento a criação da Universidade da Integração Internacional da Lusofonia Afro-brasileira - UNILAB.

Essa política, no entanto, foi parcialmente abandonada pelo governo de Dilma Rousseff e, ao menos no discurso, apresenta-se absolutamente contrária às diretrizes do atual governo, que busca a tradicional saída única de retorno aos mercados norte-americano e europeu. Compreende-se, assim, que há um longo caminho a ser percorrido entre o Brasil e os ainda recentes países africanos, de forma a superar as dificuldades que impedem o aprofundamento das relações e concretize, efetivamente, os laços que povoam o imaginário brasileiro.

\section{Referências}

AGÊNCIA BRASILEIRA DE COOPERAÇÃO. A cooperação técnica do Brasil para a África. ABC: Brasília, 2010. 
AMORIM, CELSO. Discursos, palestras e artigos do Chanceler Celso Amorim: 2003-2010. v.l. Brasília: Ministério das Relações Exteriores, Departamento de Comunicação e Documentação: Coordenação-Geral de Documentação Diplomática, 2011.

BNDES. BNDES Exim. Disponível em:

$<$ http://www.bndes.gov.br/SiteBNDES/bndes/bndes_pt/Institucional/Apoio_Financeiro/Produtos/B NDES_Exim/index.html>. Acesso em: 07 abril 2014.

CARNEIRO, Ricardo. Desenvolvimento em crise: a economia brasileira no último quarto do século XX. São Paulo: Editora Unesp, IE-Unicamp, 2002.

CAU, Hilário Simões. A construção do Estado em Moçambique e as relações com o Brasil. 2011. 132f. Tese (Doutorado em Ciência Política) - Instituto de Filosofia e Ciências Humanas, Universidade Federal do Rio Grande do Sul, Porto Alegre, 2011.

CERVO, Amado Luiz. Parte III: Do projeto desenvolvimentista à globalização. In: CERVO, Amado Luiz; BUENO, Clodoaldo. História da política exterior do Brasil. Brasília: Editora Universidade de Brasília, 2012. $4^{\mathrm{a}}$ ed.

DANTAS, San Tiago. Política Externa Independente. Editora civilização Brasileira: Rio de Janeiro, 1962.

DÁVILA, Jerry. Hotel Trópico: o Brasil e o desafio da descolonização africana, 1950-1980. São Paulo: Paz e Terra, 2011.

DINIZ, Eli; BOSCHI, Renato R. A difícil rota do desenvolvimento: empresários e a agenda pósneoliberal. Belo Horizonte: Editora UFMG; Rio de Janeiro: IUPERJ, 2007.

EMBAIXADA DO BRASIL EM LISBOA. A Comunidade dos Países de Língua Portuguesa. Lisboa, nov. 1994 .

FONSECA, Luiz Henrique Pereira da. La visión de Brasil sobre La cooperación internacional. In: Revista Española de Desarrolo y Cooperación, n. 22, primavera/verano, 2008.

FONSECA, Pedro Cezar Dutra; CUNHA, André Moreira; BICHARA, Julimar da Silva. O Brasil na era Lula: retorno ao desenvolvimentismo. Disponível em: <

http://www.reded.net.br/index.php?option=com_jdownloads\&ltemid=419\&view=viewdownload\&c atid=14\&cid=179\&lang=pt\#.UOn_KORXo_g>. Acesso em: 13 nov. 2012.

GONÇALVES, Williams da Silva. O realismo da fraternidade: Brasil-Portugal. Lisboa: Imprensa de Ciências Sociais, 2003.

LEITE, Patrícia Soares. O Brasil e a cooperação sul-sul em três momentos de política externa: os governos Jânio Quadros, João Goulart, Ernesto Geisel e Luiz Inácio Lula da Silva. Fundação Alexandre Gusmão: Brasília, 2011.

LEME, Rafael Souza Campos de Moraes. Absurdos e Milagres: um estudo sobre a política externa do lusotropicalismo (1930-1960). Brasília: Funag, 2011.

LOPES, Luís Ferreira; SANTOS, Octávio dos. Os novos descobrimentos: do império à CPLP: ensaios sobre história, política, economia e cultura lusófonas. Coimbra: Almedina, 2006. 
MAGALHÃES, José Calvet de. Relance histórico das relações diplomáticas luso-brasileiras. Lisboa: Quetzal, 1997.

MANIFESTO DE FUNDAÇÃO DO PT. Disponível em:

<http://www.pt.org.br/arquivos/manifestodefundacaopt2.pdf>. Acesso em: 13 fev. 2013.

MENEZES, A. J. Bezerra de. Ásia, África e a política independente do Brasil. Rio de Janeiro: Zahar Editores, 1967.

MINISTÉRIO DAS RELAÇÕES EXTERIORES. Visitas internacionais do Presidente Lula e visitas ao Brasil de Chefes de Estado e de Chefes de Governo - 2003 a 2010. Brasília, 2011. Disponível em: http://www.itamaraty.gov.br/temas/balanco-de-politica-externa-2003-2010/visitas-internacionaisdo-presidente-lula-e-visitas-ao-brasil-de-chefes-de-estado-e-de-chefes-de-governo-2003-a2010/view. Acesso em 13 fev 2013.

MOSCA, João; SELEMANE, Tomás. Mega-projectos no meio rural, desenvolvimento do território e pobreza: o caso de Tete. In: BRITO, Luis de; CASTEL-BRANCO, Carlos Nuno; CHICHAVA, Sérgio; FRANCISCO, António (orgs.). Desafios para Moçambique 2012. Maputo: IESE, 2012.

MOURÃO, Fernando Augusto Albuquerque; CARDOSO, Fernando Jorge; OLIVEIRA, Henrique Altemani de. As relações Brasil-África: de 1990 a 2005. In: OLIVEIRA, Henrique Altemani de; LESSA, Antônio Carlos (Orgs.). Relações Internacionais do Brasil: temas e agendas. v.1. São Paulo: Saraiva, 2006.

RODRIGUES, José Honório. Brasil e África: outro horizonte. 2. ed. Rio de Janeiro: Editora Civilização Brasileiro, 1964, v.1.

Brasil e África: outro horizonte. 2. ed. Rio de Janeiro: Editora Civilização Brasileiro, 1964,

V.2.

SATO, Eiiti. 40 anos de política externa brasileira, 1958-1998: três reflexões. Rev. Bras. Polit. Int., n.41, 1998, p.8-28.

SARAIVA, José Flávio Sombra. África parceira do Brasil atlântico: relações internacionais do Brasil e da África no início do século XXI. Belo Horizonte: Editora Fino Traço, 2012.

SILVA, Márcia Maro da. A independência de Angola. Brasília: Fundação Alexandre Gusmão, 2008.

SILVA, Silvio José Albuquerque e. Combate ao racismo. Brasília: Fundação Alexandre de Gusmão, 2008.

SINGER, André. Os sentidos do Lulismo: reforma gradual e pacto conservador. São Paulo:

Companhia das Letras, 2012.

VALOR ECONÔMICO. Brasil quer replicar com outros países da África modelo de comércio com Angola. Quarta-feira, 2 de maio de 2012. (Impresso)

VIGEVANI, Tullo; CEPALUNI, Gabriel. A política externa de Lula da Silva: a estratégia da autonomia pela diversificação. Contexto Internacional. Rio de Janeiro, v. 29, n. 2, p. 273-335, jul/dez., 2007. 


\section{Abstract}

The analysis of recent years of political and economic relations between Brazil and African countries shows a tendency to repeat a pattern present throughout the 2oth century - short periods of approximation followed by longer periods of distance. The importance of the African heritage to the formation of the Brazilian society has not been reflected in the construction of stable relations with some of these countries or that are dynamized and deepen over time. This article tries to present the dynamics of distance-approximation that has characterized these relations, bringing elements that make possible to understand the maintenance of this pattern.

Keywords: Brazil. African countries. Relations. Dynamics. 